\title{
Acute Peritoneal Dialysis in African Pediatric Area Experience of Pediatric Nephrology Unit of Yopougon University Hospital (Abidjan, Côte d'Ivoire)
}

\author{
Gnenefoly Diarrassouba ${ }^{a} \quad$ Laurence Adonis-Koffy $^{a} \quad$ Ekou Niamien $^{a}$ \\ Jean Baptiste Yaokreh ${ }^{b}$ Pessa Albert Coulibaly ${ }^{a}$

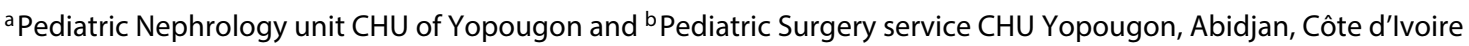

\section{Key Words}

Children · Peritoneal dialysis · Renal failure · Africa

\begin{abstract}
Introduction: Acute kidney injury (AKI) is a diagnostic emergency threatening patients in a major way. Pediatric renal extra purification methods are limited in African countries due to the nonavailability of resources. Peritoneal dialysis (PD) seems to be the modality that is the most practiced for children with acute renal failure (ARF). Methodology: We conducted a retrospective study on 5 years of records of children from 1 month to 15 years who have suffered an ARF and benefited from PD while being treated at the pediatric nephrology unit of the Chu of Yopougon. ARF is defined as the condition that exists when the serum creatinine level is high or equal to $200 \mu \mathrm{mol} / \mathrm{l}$ outside any underlying uropathies. Results: Out of the hospitalized 88 children for AKI, 33 were on PD. Twenty-two children have been on dialysis while 9 children had to discontinue treatment due to financial problems. The sex ratio was 0.46 and the average age was 8.1. The etiologies of the AKI were predominantly glomerular diseases (45\%), malaria (31.8\%), and secondary interstitial nephritis of toxic origin. The indications of the PD
\end{abstract}

are anuria (31\%), hyperkalemia (18\%), acute edema of lung (13\%), and hyperuremia (13\%). Eight children had automated peritoneal dialysis, 02 children underwent manual PD, and 9 children had both methods of treatment. We recorded 31 mechanical complications and 10 infections. While 8 children died, 10 recovered from AKI. Conclusion: Trained surgical medical personnel and favorable economic statuses of patients are the factors that will determine the success of PD in our country.

(c) 2015 S. Karger AG, Basel

\section{Introduction}

Acute renal failure (ARF) marked by the reduction or end of glomerular filtration must be detected early because it can quickly lead to hydroelectrolytic disorder involving life-threatening conditions, such as the risk of acute edema of the lung (AEL) linked to the water overload and hyperkalemia cardiac pace disorders [1].

The authors state that there is no conflict of interest.

\section{KARGER 125}

(c) 2015 S. Karger AG, Base

0253-5068/15/0393-0141\$39.50/0

E-Mail karger@karger.com

www.karger.com/bpu
Diarrassouba Gnenefoly

Pediatric Unit Nephrology of Yopougon University Hospital 04 BP 1418 Abidjan 04 (Côte d'Ivoire)

E-Mail diarrassoubag@yahoo.fr 
The two general methods of treatment for kidney disease are hemodialysis (HD) and peritoneal dialysis (PD). Of these two methods, peritoneal dialysis appears to be the most feasible in children in developing countries, because it is cost effective and does not required a high financial status $[2,3]$.

In sub-Saharan Africa, PD is not practiced to a great extent and so data on this activity are scarce. Until 2008, no private or public medical structure in Ivory Coast had a pediatric dialysis unit. Children weighing more than $30 \mathrm{~kg}$, benefited from hemodialysis with material originally intended for adults. Since 2008, the advent of a unit of pediatric nephrology (UNP) in Abidjan (Côte d'Ivoire) allowed the practice of PD.

\section{Aim}

The objective of this study was to analyze the activity of PD (epidemiological, clinical, technical aspects, and evolving) in children with disease-acute renal failure in the unit of pediatric nephrology of the CHU of Yopougon in Côte d'Ivoire after five years of its initiation.

\section{Methods}

The UNP opened its doors to the Yopougon University Hospital in December 2008 (the first unit of pediatric nephrology of French-speaking black Africa) and with it the PD was introduced in Côte d'Ivoire.

Pediatric nephrology hospitalization admission is done from the consultations of pediatric Nephrology or from children received in the emergency and/or in the pediatrics unit of the CHU of Yopougon and admitted in pediatric nephrology after the doctor permanently or penalty notice. Admission may also be made from other medical structures like public or private hospitals based on the opinions of the doctors of the pediatric nephrology unit. We conducted a retrospective study of records of children from 1 month to 15 years who presented with acute renal failure (ARF); this study was supported by the team of the pediatric nephrology unit (UNP) of the CHU of Yopougon and having benefited of a PD during acute. ARF in infants and older children was defined by a condition when plasma creatinine was greater than or equal to $200 \mu \mathrm{mol} / \mathrm{l}$. Children with underlying renal disease were excluded. Children with AKI and an obstructive uropathy diagnosed in antenatal (posterior urethral valves) were not included in the study. All children undergoing catheters dialysis were placed in a surgical manner under general anesthesia by a surgeon pediatrician more often 'referent' and 'dedicated.' The laying of the catheter lasts for an average of 30 to $45 \mathrm{~min}$.

The PD has either been automated peritoneal dialysis (CAPD) on cycler and/or manual peritoneal dialysis (CAPD) with solutes of $1.26 \%$ and $2.27 \%$ glucose concentration. Using a form of inquiry, data was gathered on sex, age, the socioeconomic level of the parents, the etiology of renal failure, the indication of the PD and the technic used, and the clinical course.

\section{Results}

During the period of study, the UNP made 252 hospitalizations including 88 for insufficient renal acute failure. 22 children have been dialysis on 33 who had an indication of PD (average 4-5 dialysis patients per year). 9 children of the 11 who are not undergoing dialysis summers, the financial problems of the parents (27.3\%) was the cause of non-realization of PD. 01 child has been evacuated abroad according to the will of the parents and 01 child hemodynamic instability against indicated general anesthesia. The sex ratio was 0.46 (7/15); the average age of the children undergoing dialysis was 8.1 years with extremes from 1 to 15 years. The etiologies (fig. 1) of the AKI in our unit were the glomerular diseases (45\%), malaria (31.8\%), and secondary tubulointerstitial nephritis to the use of toxic drug. The indications to use the PD modality were anuria (31\%), hyperkalemia (18\%), edema acutelung (13\%), and hyperuremia (13\%). All catheters were placed surgically in the operating room after consultation by a pre anesthetic by a senior surgeon pediatrician [5]. The Tenckhoff catheter was used in 20 children (20/22) and was used at 02 Drain in Redon. The median time to onset of complications was 03 days. Peritonitis and infections (08/10) were diagnosed after clinical data confrontation (turbid liquid and or abdominal pain and or fever) and as a result of the tests done in the bacteriological laboratory, 4 germs were isolated in the dialysate fluid (table 1). The techniques used were automated peritoneal dialysis (APD) in 8 children, manual peritoneal dialysis (CAPD) in 2 children, and 9 patients were associated with APD and CAPD. 17 of 22 patients have presented a complication with a prevalence of 77. Complications have resulted in transient discontinuation of the PD (17 cases), final judgment (8 cases), and a repeat surgery for placement of catheter ( 9 cases) resulting in an increase in the length of hospital stay and expenses. The overall trend (fig. 2) after causal and symptomatic support associated with the PD shows that the rate of recovery of renal function in 10 patients is $45 \%$; four patients evolved toward chronic renal failure while 8 patients died (36\%). The main complications were of mechanical origin (lack of drainage from the peritoneal cavity) in 31 cases and infectious complications in 10 cases (table 1). The etiologies of deaths in our study were the AEL (2 cases), hyperkalemia ( 2 cases), anemia (01 case), and 2 deaths were due to infections (nosocomial Infection in Acinobacter and complicated Tunelites of secondary sepsis with disorder of coagulation). 
Fig. 1. Causes of AKI.

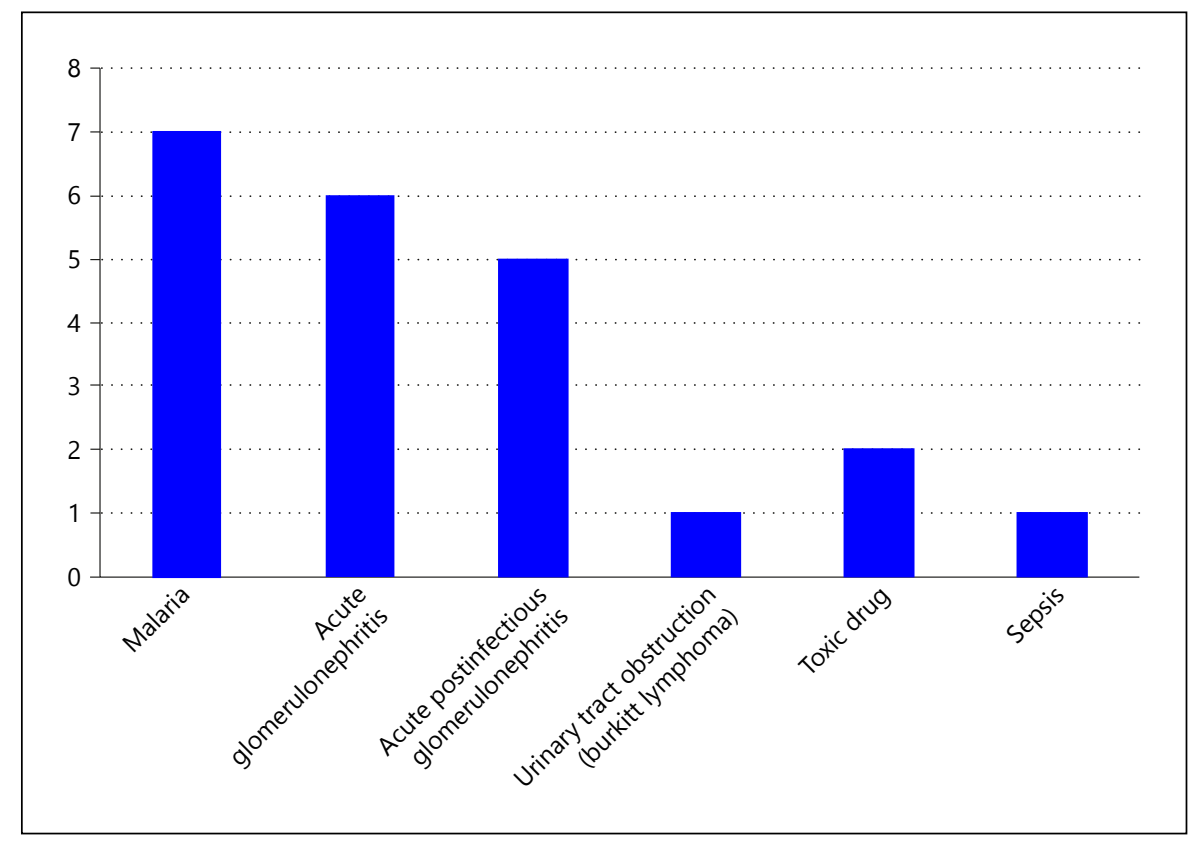

Fig. 2. Overall evolution of patients.

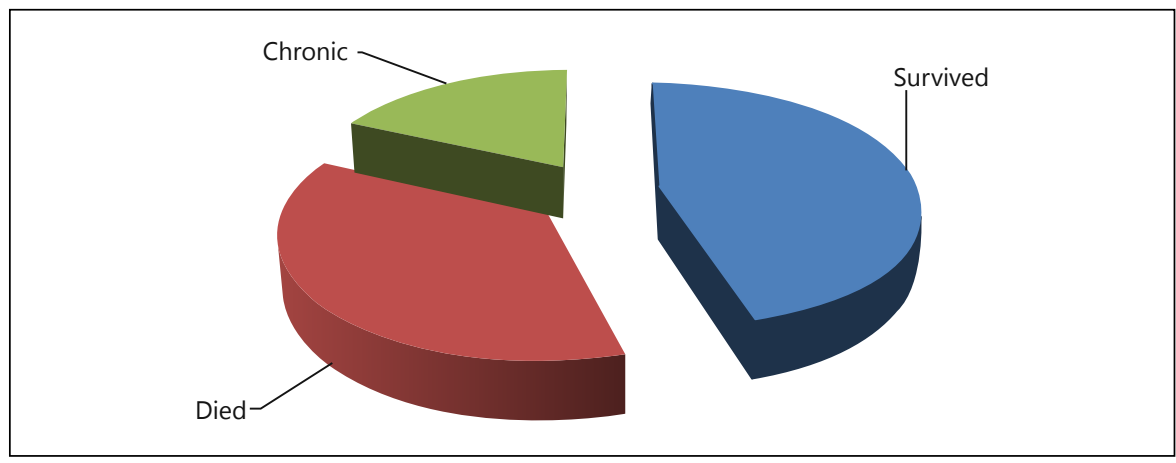

\section{Discussion}

Studies of Olowu [5] in Nigeria reveal the financial problem that is present there; in Aloni only $10.9 \%$ of patients have the ability to gain access to PD and in the Congo [6] only $26 \%$ of patients have that capacity. The conditions of admission to the UNP are not always within the reach of the financial capacities of the parents. In fact, only two parents had health insurance but even in that scheme had to pay upfront and then collect the reimbursement from the insurance company. In our developing country, glomerulopathies, which are the main etiology for AKI, is found to predominantly affect children in the age group 2 to 15 [7]. Acute tubular necrosis is the principal renal manifestation of severe malaria caused by Plasmodium falciparum, responsible of AKI in our study
Table 1. Etiologies of germs isolated from infectious complications

\begin{tabular}{ll}
\hline Presence of germs & 04 \\
& $\begin{array}{l}\text { Staphylococcus aureus } \\
\text { Klesiella pneumoniae } \\
\text { Acinobacter } \\
\text { Proteus mirabilis }\end{array}$ \\
\hline Absence of germs & 06 \\
\hline
\end{tabular}

and is responsible for $31.8 \%$ of the AKI in PD. Malaria is present in work on renal failure in Group III of malaria $[5,8,9]$ countries. Gastroenteritis (ANOCHIE in Nigeria and ASSOUNGA in the Congo as etiology of the AKI in the child) and hemolytic uremic syndrome (HUS) diarrheal post (the most frequent etiology of the AKI in chil- 
dren in Europe $[10,11])$, have not been found as causes for AKI in our study probably because diarrhea gets treated in pediatric services and the absence of HUS may be due to our eating habits that make foods are prepared over cooked. The indication of PD in the AKI is strongly influenced by hyperkalemia due to the risk of cardiac arrest by pace disorders and acute lung and cerebral edema leading to salt and water retention. PD was a renal extra purification technique used in our unity because it is the only method available; also, it has the benefit of being just a simple procedure where the peritoneum can be easily hyperpermeable in infants and small children [3] and this all the more the production of vascular first is often difficult. Redon drains have been used in low-weight children $(<10 \mathrm{~kg})$ and for which the diameter of the Tenckhoff catheter we had was not suitable.

The Tenckhoff catheter has the advantage of having fewer problems of dysfunction and the catheters that are placed at the bedside without a cuff have a long life [12]. The installation of the KT is a time key that is vital in the realization of the PD program. It is necessary to have a surgeon as part of the team coordinated by the nephrologist in order to avoid complications. Peritonitis was treated according to the recommendations of the international society for peritoneal dialysis [13] (with empirical antibiotics aimed at both Gram positive and Gram negative germs). Ceftriaxon was used as first-line intravenous associated with washouts intra peritoneal with the liquid of dialysate containing Ceftriaxon on periods of stasis of the dialysate of short duration. This protocol was amended according to the results of culture and antibiotic susceptibility testing. The death rate in our country is higher than that of Bourquia ( $17 \%$ in the Morocco), which is a country where the practice of the PD is the oldest and the most developed, and according to the Anochie study, it is lower than the death rate $(40.5 \%)$ in Nigeria where gastroenteritis was the main etiology. Overall, renal damage is typically not the cause of mortality in renal failure; this mainly depends on the associated extra kidney damage and the hemodynamic state. The degree of circulatory overload and the amines vasopressives needs have emerged as poor prognosis factors in recent studies [14-16].

\section{Conclusion}

PD is an extra kidney cleansing technique that deserves to be developed in West Africa, particularly in the pediatric environment. The cost of the PD remains important because of the lack of a social security body. It appears at the end of our study that the success of the method and the decline in the mortality rate can be guaranteed only by ensuring efficient multidisciplinary training involving surgical staff, nurses and biologists, and by creating awareness in every state on the importance of pediatric nephrology in our countries.

\section{References}

1 Macher MA: Insuffisance rénale aiguë chez l'enfant, EMC, Paris Elsevier Ed, Pédiatrie, 4-084-D-20, 2004

2 Diallo I: Centre hospitalier régional de St Louis du Sénégal. Place de la dialyse Péritonéale comme méthode de traitement par excellence de l'insuffisance rénale terminale dans les pays en voie de développement [Internet]. Consulté le 10 décembre 2010. Disponible sur: http://hopital-saintlouis.sn/component/ content/article/34-actu-sant/136-analysedialyse-ptone.

-3 Adebowale DA, Adanze OA, Oluwatoyin OO, et al: Peritoneal dialysis in childhood acute kidney injury: experience in southwest Nigeria Perit Dial Int 2012;32:267-272.

4 Crabtree JH: Who should place peritoneal dialysis catheters? Perit Dial Int 2010;30:142150.

5 Olowu WA: Renal failure in Nigerian children: factors limiting access to dialysis. Pediatr Nephrol 2003;18:1249-1254.
6 Aloni MN, Nsibu CN, Meeko-Mimaniye M, Ekulu PM, Bodi JM: Acute renal failure in Congolese children: a tertiary institution experience. Acta Paediatr 2012;101:e514-e518.

7 Bourquia A: L'insuffisance rénale aiguë chez l'enfant marocain: Etude à propos de 100 cas. Revue maghrébine de Pédiatrie 1999, vol. 9, $\mathrm{n}^{\circ}$ 5, pp 237-242 $6 \mathrm{p}$.

-8 Anochie IC, Eke FU: Paediatric acute peritoneal dialysis in southern Nigeria. Postgrad Med J 2006;82:228-230.

9 Assounga AG, Assambo-Kieli C, Mafoua A, et al: Etiology and outcome of renal failure in congo-brazzaville. Saudi J Kidney Dis Transpl 2000;11:40-43.

10 Moghal NE, Brocklebank JT, Meadow SR: A review of acute renal failure in children: incidence, etiology and outcome. Clin Nephrol 1998;49:91-95.

11 Loirat C, Taylor CM: Hemolytic uremic syndromes; in Avner ED, Harmon WE, Niaudet $\mathrm{P}$ (eds): Pediatric nephrology ed 5. Lippincott Williams \& Wilkins, 2004, pp 887-915.
12 Chadha V, Warady BA, Blowey DL, et al: Tenckhoff catheters prove superior to cook catheters in pediatric acute peritoneal dialysis. Am J Kidney Dis 2000;35:1111-1116.

13 Li PK, Szeto CC, Piraino B, et al; ISPD Guidelines/Recommendations: Peritoneal dialysisrelated infections recommendations: 2010 update. Perit Dial Int 2010;30:393-423.

14 Goldstein SL, Somers MJ, Baum MA, Symons $\mathrm{JM}$, et al: Pediatric patients with multi-organ dysfunction syndrome receiving continuous renal replacement therapy. Kidney Int 2005; 67:653-658.

15 Foland JA, Fortenberry JD, Warshaw BL, et al: Fluid overload before continuous hemofiltration and survival in critically ill children: a retrospective analysis. Crit Care Med 2004;32: 1771-1776.

16 Bunchman TE, McBryde KD, Mottes TE, et al: Pediatric acute renal failure: outcome by modality and disease. Pediatr Nephrol 2001; 16:1067-1071. 